Del Día de la Mujer al Paro Internacional de Mujeres. ¿Qué es el 8 de Marzo para el diario El Día?

Flavia Delmas, Marianela García, Mercedes Yurec, Manuela Paradela, Eugenia Bustamante, Luciana Isa

Con X (N. ${ }^{\circ}$ ), e032, 2020

ISSN 2469-0333 | https://doi.org/10.24215/24690333e032

http://perio.unlp.edu.ar/ojs/index.php/conequis

FPyCS | Universidad Nacional de La Plata

La Plata | Buenos Aires | Argentina

\title{
Del Día de la Mujer al Paro Internacional de Mujeres
}

From Women's Day to the Women's International Strike

\begin{abstract}
Flavia Delmas
marinallanura@gmail.com

Marianela García

marianela.perio@gmail.com

https://orcid.org/0000-0002-6956-9655

https://orcid.org/0000-0003-4970-6031

Mercedes Yurec

mechi.yurec@hotmail.com

Manuela Paradela

mparadela@perio.unlp.edu.ar

https://orcid.org/0000-0003-4600-187X

https://orcid.org/0000-0002-0200-1635

Eugenia Bustamante

ebustamante@perio.unlp.edu.ar

Luciana Isa

lucianaisa@perio.unlp.edu.ar

https://orcid.org/0000-0002-6514-9151

\section{Observatorio de Comunicación, Estudios de Género y Movimientos Feministas Facultad de Periodismo y Comunicación Social \\ Universidad Nacional de La Plata | Argentina}

\section{Resumen}

Las autoras, integrantes del Observatorio de Comunicación, Estudios de Género y Movimientos Feministas de la Secretaría de Género de la Facultad de Periodismo y Comunicación Social de la Universidad Nacional de La Plata, analizan el relato mediático sobre el 8M construido por el diario El Día, de la ciudad de La Plata (Buenos Aires, Argentina), durante el período 2009-2019.

Palabras clave | Día de la Mujer, Paro Internacional de Mujeres, relato mediático, El Día

\section{Abstract}

The authors, members of the Observatory of Communication, Gender Studies and Feminist Movements of the Gender Secretariat of the Facultad de Periodismo y Comunicación Social of the Universidad Nacional de La Plata, analyze the media story about the $8 \mathrm{M}$ built by the newspaper El Día, from the city of La Plata (Buenos Aires, Argentina), during the period 2009-2019.
\end{abstract}

Keywords | Women's Day, Women's International Strike, media story, El Día 


\title{
Del Día de la Mujer al Paro Internacional de Mujeres \\ ¿Qué es el 8 de Marzo para el diario El Día?
}

\author{
Por Flavia Delmas, Marianela García, \\ Mercedes Yurec, Manuela Paradela, \\ Eugenia Bustamante y Luciana Isa
}

El 8 de Marzo es una fecha clave de conmemoración y de lucha de las mujeres en todo el mundo. En la Argentina, luego de la sanción de Ley Nacional 26.743 de Identidad de Género (2012) y del avance de los colectivos de lesbianas, trans, travestis y bisexuales, se ha ampliado el nombre y, por lo tanto, su sentido. Esa «s», que marca el plural y la diferencia, la disidencia de quienes no soportamos el peso de la hegemonía cristalizada en las normas de la exclusión, nos señala, también, que se han ampliado los márgenes de quienes desde hace más de doscientos siglos enfrentamos a un poder patriarcal que nos asfixia en una violencia cotidiana, que se traduce en cada ámbito donde desarrollamos nuestras vidas: en el acceso a trabajos dignos, en la posibilidad de un buen vivir, sin colonialismos disfrazados de modernidad ni imperialismos escondidos en discursos de falsas democracias.

Tras cuatro años en los que pareció no haber momento para el sosiego por la profundidad de la crisis, cuyo sostén está compuesto por los dueños de todas las cosas, que en la actualidad se instalan en una tríada despiadada por su efectividad para el despojo: poder ejecutivo, poder judicial y medios de comunicación, realizamos el trabajo de análisis que aquí se ofrece sobre este último y sobre las mutaciones que oscilan entre la violencia simbólica y el reconocimiento de los derechos. 
La prensa no siempre nos nombró de igual manera: desde las entrañas de la invisibilización, pasando por la construcción de una otredad inferior y por la objetualización de nuestros cuerpos como bienes mercantiles, a la puja por la agenda mediática en un contexto de avanzada del movimiento feminista en la Argentina y en gran parte del mundo.

Desde el Observatorio de Comunicación, Estudios de Género y Movimientos Feministas de la Secretaría de Género de la Facultad de Periodismo y Comunicación Social de la Universidad Nacional de La Plata, nos preguntamos acerca de la configuración del relato mediático sobre el $8 \mathrm{M}$ y realizamos un recorrido por diez años de publicaciones sobre dicha efeméride en el diario tradicional de nuestra ciudad: El Día.

Entre notas de tapa, artículos contextuales y publicidades, cada 8 de Marzo el diario construyó la noticia y presentó a su público lector una forma de comprender a las mujeres desde estereotipos de lo más trillados, marcando el límite y las consecuentes transgresiones de las mujeres a los deberes, los saberes y las formas de lo concebido como «masculino».

Este tipo de construcciones hegemónicas dan soporte a lo que la investigadora mexicana Elsa Muñiz García (1999) categoriza como la cultura de género. Es decir, que los medios de comunicación crean y reproducen elaboraciones simbólicas hegemónicas de lo femenino y lo masculino que se traducen en códigos de conducta sociales tanto en el ámbito privado como en el público. En este sentido, la cultura del género se configura como uno de los soportes más sólidos para la legitimación del poder y del sistema político en el mundo globalizado.

Esta propuesta teórica nos permite contextualizar la presencia de las feminidades en diversos escenarios sociales, entre ellos, los medios de comunicación, y posibilita que nos preguntemos en qué medida el poder continúa ocupando el cuerpo de las mujeres como una política sexual que se actualiza a demanda de una sociedad permeada por la lógica del capital: vincularidad efímera e individualismo constitutivo, mediante los cuales las desigualdades se vuelven menos evidentes aunque para nada se disipan: la dominación masculina se renueva y se mantiene. 


\section{M 2019: el contexto de una lucha}

El neoliberalismo reinante, con su halo de cinismo desvergonzado, nos sumerge en el endeudamiento de generaciones enteras, en la persecución política, en el hambre y el empobrecimiento de amplios sectores, en el crecimiento de la desocupación y el cierre de lugares de trabajo, en travesticidios, transfemicidios y feminicidios en alza permanente por su reiteración y su crueldad, en el extractivismo y sus nefastas consecuencias para la salud de las poblaciones, en el despojo de la tierra y la persecución constante de los pueblos indígenas, en los asesinatos de jóvenes víctimas del gatillo fácil, en la desaparición de mujeres, niñas y niños en manos de redes de trata para la explotación sexual, en las violaciones en manada, entre otros tantos pesares que merecen tener fin de una vez por todas y que forman parte de un rompecabezas cuyas disímiles piezas se encastran sin dificultad en una composición trágica.

Es preciso que reparemos en algunos acontecimientos y en datos que describen con agudeza una realidad de la que solo se sale si apelamos a la memoria colectiva, a la estrategia política, a la decisión de erradicar la indiferencia, de romper el aislamiento y de apostar por la organización de las mayorías.

En principio, cabe señalar que 2019 se presenta en un contexto de aumento del desempleo y la pobreza. Las cifras económicas y financieras de nuestro país no señalan un panorama favorable en el corto plazo. Al mismo tiempo, el gobierno nacional nos ha endeudado con el Fondo Monetario Internacional (FMI) a cien años. En ese marco, debemos mirar qué sucede con el empleo de las mujeres en la Argentina. De acuerdo con un informe realizado por Nora Goren y por David Trajtenberg (2018) para la Fundación Friedrich Ebert, la situación laboral de las mujeres en la Argentina es la siguiente:

* En 2017, las mujeres percibían, en promedio, un salario 25\% menor al que cobraban los varones (p. 10).

- El empleo femenino se concentra en unas pocas ramas de actividad, la más significativa de las cuales es el trabajo en casas particulares, que explica $23 \%$ del empleo femenino asalariado, y que, junto con el empleo en las ramas de enseñanza y de salud, explican la mitad del empleo asalariado femenino (p. 11). 
- Las mujeres perciben menores remuneraciones que los varones en todas las ramas de actividad (p. 11).

• El salario mensual de la ocupación principal de mujeres que trabajan en casas particulares resulta el más bajo de todas las ramas de actividad, tanto de varones como de mujeres (p.12).

- Las mujeres con dos o más menores en el hogar trabajan en promedio una menor cantidad de horas que los varones [...] y en 2017 percibieron una remuneración mensual inferior en un 35\% (p. 15).

En un trabajo sobre los datos de la Encuesta Permanente de Hogares para el tercer trimestre de 2018, Natusumi Shokida (2019) realiza los siguientes señalamientos:

- Son las mujeres más jóvenes las que presentan menores tasas de actividad y empleo.

- Las mujeres enfrentan mayores niveles de empleo no registrado. Hay un $37 \%$ de trabajadoras asalariadas a quienes sus empleadores no inscriben en la seguridad social, mientras que para los asalariados varones esta tasa de no registro es de $32,1 \%$.

- Además de tener una participación más restringida en el mercado de trabajo, las ocupadas encuentran más obstáculos para acceder a cargos jerárquicos.

- De los ingresos totales individuales de toda la población, se desprende que la brecha entre varones y mujeres es de 26,2 puntos porcentuales. Es decir, si se contemplan todos los ingresos que se perciben, sean de origen laboral o no laboral (como jubilaciones y pensiones, cuotas alimentarias, subsidios, entre otros), las mujeres perciben ingresos que, en promedio, son $26,2 \%$ menores que los de los varones.

- En el mercado de trabajo las mujeres ganan en promedio $25,2 \%$ menos que los varones. Estos datos corresponden a la totalidad de personas ocupadas, cualquiera sea su categoría ocupacional, su calificación o su jerarquía, y observando en este caso los ingresos provenientes de la ocupación principal. 
- Las asalariadas presentan mayores tasas de empleos no registrados que sus pares varones. Pero, además, las asalariadas no registradas ganan, en promedio, $37,2 \%$ menos que sus pares. Es decir que la brecha de ingresos se amplía para quienes tienen peores condiciones de trabajo.

- La brecha de ingresos mensuales de las personas ocupadas se mantiene incluso a iguales niveles de calificación. Las mujeres ocupadas en el mismo segmento profesional perciben $20,4 \%$ menos que los varones, mientras que en los puestos no calificados la brecha asciende a $38,6 \%$.

- Las mujeres ocupadas están en promedio más formadas que los varones que participan en el mercado de trabajo. Sin embargo, a igual nivel educativo, los ingresos laborales de las mujeres trabajadoras son inferiores a los de los varones. Esta diferencia de ingresos es de 26,9\% para las de nivel universitario / superior, y de $46,2 \%$ para las que cuentan con nivel primario.

- En general, las mujeres deben dedicar parte de su tiempo al trabajo doméstico. Es decir, realizan tareas de cuidado y de reproducción para otros miembros de su hogar. Este trabajo no se comercia en el mercado y, por tanto, no es remunerado. Del total de personas que realizan este tipo de tareas, $75 \%$ son mujeres y $25 \%$ son varones.

En tanto, la Cooperativa de Comunicación Feminista Manifiesta (2019) publicó que, en 2018, 91\% de personas trans y travestis no tenían trabajo registrado y que $82 \%$ lo atribuía a la discriminación por identidad y/o por expresión de género. En este sentido, se vuelve necesario que el Congreso de la Nación apruebe la ley nacional Diana Sacayán de Cupo Laboral Trans.

\section{El derecho a la salud y las dificultades para el acceso}

Para 2020, queda el desafío en materia de sexualidad y de acceso al derecho a la salud de mujeres y de niñas, que en la Argentina aún es restrictivo, aunque sin dejar de tener en cuenta el reciente anuncio del Poder Ejecutivo de enviar al Congreso un nuevo proyecto de ley de Interrupción Voluntaria del Embarazo (IVE). ${ }^{1}$ 
$\mathrm{Al}$ respecto, en el informe dado a conocer en octubre de 2018, el Comité sobre los Derechos del Niño de Naciones Unidas señaló su profunda preocupación «por los informes sobre la persistencia de la discriminación de hecho, la exclusión social y los abusos físicos, sexuales y psicológicos que sufren los niños por motivos de discapacidad, por su origen indígena o por su condición socioeconómica» (art. 14, en línea) e instó al Estado a garantizar:

- «que los niños que viven en zonas rurales y en comunidades indígenas no sean objeto de discriminación con respecto al acceso a una educación de calidad, a una atención adecuada de la salud y a la vivienda» (art. 14, inc. c, en línea),

ص "que la educación sobre salud sexual y reproductiva forme parte del plan de estudios escolar obligatorio» (art. 32, inc. a, en línea),

匹 "que las adolescentes tengan acceso a servicios de aborto sin riesgo y de atención posterior al aborto, asegurándose de que la opinión de la interesada siempre sea escuchada y tenida debidamente en cuenta en el proceso de decisión» (art. 32, inc. b, en línea).

En relación con este último aspecto, en 2019 tuvieron alcance público dos casos, uno en la provincia de Jujuy y otro en la provincia de Tucumán, que constituyen una dura muestra de lo que ocurre en la Argentina, donde, según el Programa Nacional de Salud Integral en la Adolescencia (2017), «anualmente, cerca de 3.000 niñas menores de 15 años se convierten en madres» (p. 6) -en la mayoría de los casos producto de violaciones- y no tienen acceso a la Interrupción Legal de un Embarazo (ILE).

Enero de 2019: frente al caso de la niña de 12 años de Jujuy, Página / 12 señaló:

El embarazo producto de una violación de una niña de 12 años en Jujuy, a quien le obstaculizaron la ILE y le realizaron una cesárea para «salvar las dos vidas», se convirtió en ejemplo dramático del fracaso del Estado y el sistema de salud asociado a la avanzada religiosa antiderechos, que solo busca imponer poder feudal sobre los cuerpos de las mujeres (Sandá, 25/01/2019, en línea). 
Febrero de 2019: frente al caso de la niña de 11 años en Tucumán, Amnistía Internacional indicó:

La voluntad de la niña de interrumpir un embarazo fue manifestada de forma clara y libre tanto en sede judicial como en sede sanitaria, y fue la creación de barreras burocráticas lo que dilató innecesariamente la prestación exponiendo su salud, su vida y su libertad. Negar una interrupción legal del embarazo, o dilatarla, configura violencia contra la libertad reproductiva (art. 6 inc. d de la ley 26.485) y violencia obstétrica (art. 6 inc. e de la ley 26.485). Y al haber tenido como agentes de la misma a funcionarios/as del Estado, se configura un supuesto de violencia institucional inaceptable (art. 6 inc. b) censurado por la Corte Suprema de Justicia de la Nación en el fallo F.A.L. (01/03/19, en línea).

Como señala el Comité de América Latina y el Caribe para la Defensa de los Derechos de las Mujeres (CLADEM), en su resumen ejecutivo (2016), «obligar a una niña que no ha terminado de crecer a llevar a término un embarazo, ser madre y criar a un bebé debe ser considerado tortura o trato cruel, inhumano y degradante» (p. 18).

En este sentido, las y los expertos del Alto Comisionado de las Naciones Unidas para los Derechos Humanos (2018) en el informe elaborado tras concluir el $78^{\circ}$ período de sesiones en Ginebra (Suiza),

- pidieron abordar la temática de los altos porcentajes de mortalidad materna y neonatal, así como identificar las causas de la malnutrición que afecta, principalmente, a las provincias del noroeste del país.

- realizaron un llamamiento a fortalecer la lucha contra el trabajo y la explotación sexual infantil, así como contra la trata de personas [y] recomendó desarrollar políticas públicas para asistir a niñas, niños y adolescentes en situación de calle, así como a migrantes y refugiados. 
- mostraron preocupación por el daño medioambiental causado por el impacto de la minería y de agroquímicos, y recomendó implementar medidas legislativas para proteger la salud física y mental de la niñez indígena.

- instaron a desarrollar políticas de salud mental infantil y juvenil y a garantizar la prohibición de castigos corporales, tortura y violencia institucional.

\section{Feminicidios y travesticidios:}

los números de la crueldad machista y misógina

No menor resulta la creciente cifra de feminicidios y de travesticidios en la Argentina. La asociación civil Casa del Encuentro (2018) elaboró un informe en el que se presenta la sistematización del relevamiento de femicidios realizado en diversos medios nacionales y provinciales entre 2008 y 2017.

La investigación arroja algunas de las siguientes cifras:

- 2.679 femicidios y femicidios vinculados de mujeres y de niñas (de ellos, 866 ocurrieron en la provincia de Buenos Aires).

[ 268 muertes de varones y de niños en femicidios vinculados.

- 3.378 hijos e hijas quedaron sin madre (más de 66\%, menores de 18 años).

En tanto, para los primeros meses de 2019, el Observatorio de las violencias de género «Ahora que sí nos ven», presentó las siguientes cifras [Figura 1]:

- 54 femicidios durante enero y febrero, lo que da un total de un femicidio cada 26 horas.

- 20\% de las mujeres había realizado denuncias previas

y 16\% tenía medidas de restricción de acercamiento dictadas por la justicia.

• $\mathrm{Al}$ menos 42 niños y niñas quedaron huérfanos/as. 


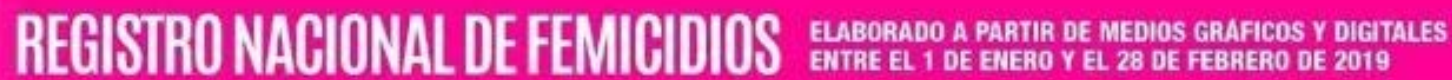

\section{FEMICIDIOS}

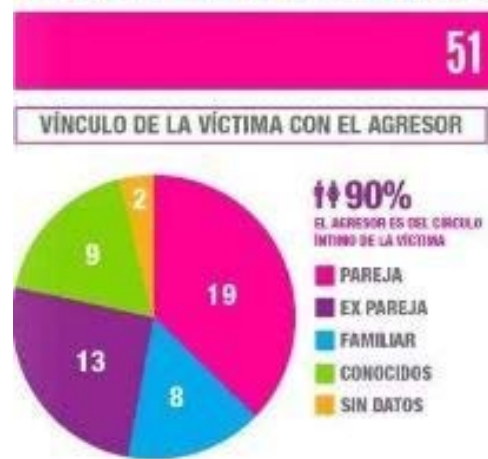

FORMAS EN LAS QUE FUERON ASESINADAS

ARMA BLANCA 11

ARMA DE FUEgO $\mathbf{r}$

AFX⿻ 28

A coupes in 8

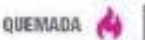

rRas/ Sin Datos?
FEMICIDIOS

FEMICIDIOS VINCULADOS VARONES Y MINOOS TRAVESTICIDIOS

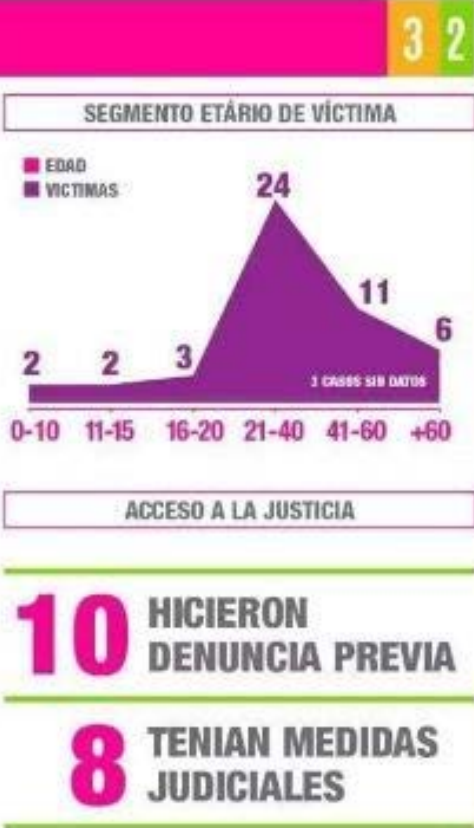

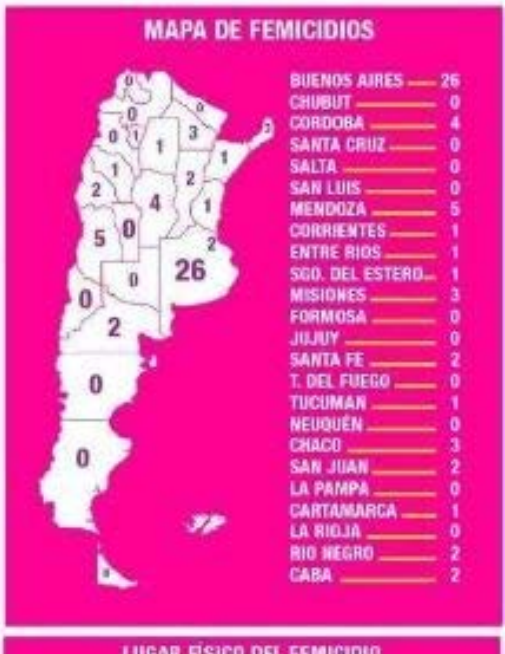

LUGAR FISICO DEL FEMICIDIO

31 Unenea 1 masaso ge u victma

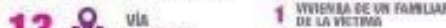

1 जाa

\section{ARORAQUE STINOS VEN}

Figura 1. Pieza elaborada por el Observatorio

«Ahora que sí nos ven» que circuló por redes sociales

En mayo de 2019, el mismo Observatorio, conducido por Raquel Vivanco, presentó ante los medios, junto a la Diputada Nacional Victoria Donda, las siguientes cifras referidas al primer cuatrimestre de 2019:

Un total de 1193 femicidios se registraron en los últimos 4 años, a razón de uno cada 29 horas, mientras que en el primer cuatrimestre de este año esa cifra aumentó a uno cada 24 horas (...)

El observatorio, que presentó el Registro Nacional de Femicidios a días de un nuevo aniversario de la marcha por el Ni Una Menos, destaca en su relevamiento que en lo que va del 2019 hubo 133 asesinatos de mujeres, siendo marzo el pico de estos delitos con un femicidio cada 23 horas (Télam, 30/05/2019, en línea). 


\section{Diez años del 8M en el diario El Día}

El diario El Día, fundado en 1884, es un diario tradicional de la ciudad La Plata, de ideología conservadora, que se ha mantenido como referencia central de la prensa local y regional a lo largo de los años. El análisis que aquí se presenta ofrece un recorrido por las notas que este medio publicó en el marco de cada 8 de Marzo durante los últimos diez años.

Este año, en la parte inferior de la portada, un pequeño recuadro menciona: «Con homenajes y reclamos se celebra el Día internacional de la mujer», y remite a las páginas 22 y 23 para ampliar el tema. En la nota principal, titulada «Ellas, con vocación de servicio», el medio ofrece «cinco historias de quienes saben muy bien qué significa ser mujer» (p. 22) [Figura 2]. Las entrevistadas son una policía, dos bomberas, una taxista y una enfermera. A partir de remarcar las cualidades personales que les permiten a estas mujeres subsistir en contextos de trabajo con clara discriminación por género, la nota pone el foco en el surgimiento de la «mujer moderna» que avanza sobre los roles laborales pensados históricamente para el hombre y no en su cuestionamiento. En el texto no se indaga sobre la ruptura del pensamiento biologicista, sino que se aclara: «Las mujeres son capaces como el hombre» (p. 23).

Como otra cara de la misma moneda, en otra información de ese día, titulada «Día de la Mujer: una de cada tres es víctima de abusos en el mundo», se alerta sobre los problemas de derechos humanos que padecen las mujeres. En el texto se indica que en la Argentina una de cada tres mujeres es víctima de abuso, según datos del Fondo de Población de Naciones Unidas (UNFPA), y que más de la mitad de las mujeres no hace la denuncia, de acuerdo a la Organización Panamericana de la Salud (OPS).

El diario también menciona las actividades realizadas en la ciudad con motivo del Día internacional de la Mujer, entre las que predominan las expresiones artísticas, en las que cantantes como Adriana Varela, Patricia Sosa y Eleonora Cassano son la atracción principal en Plaza Moreno. 


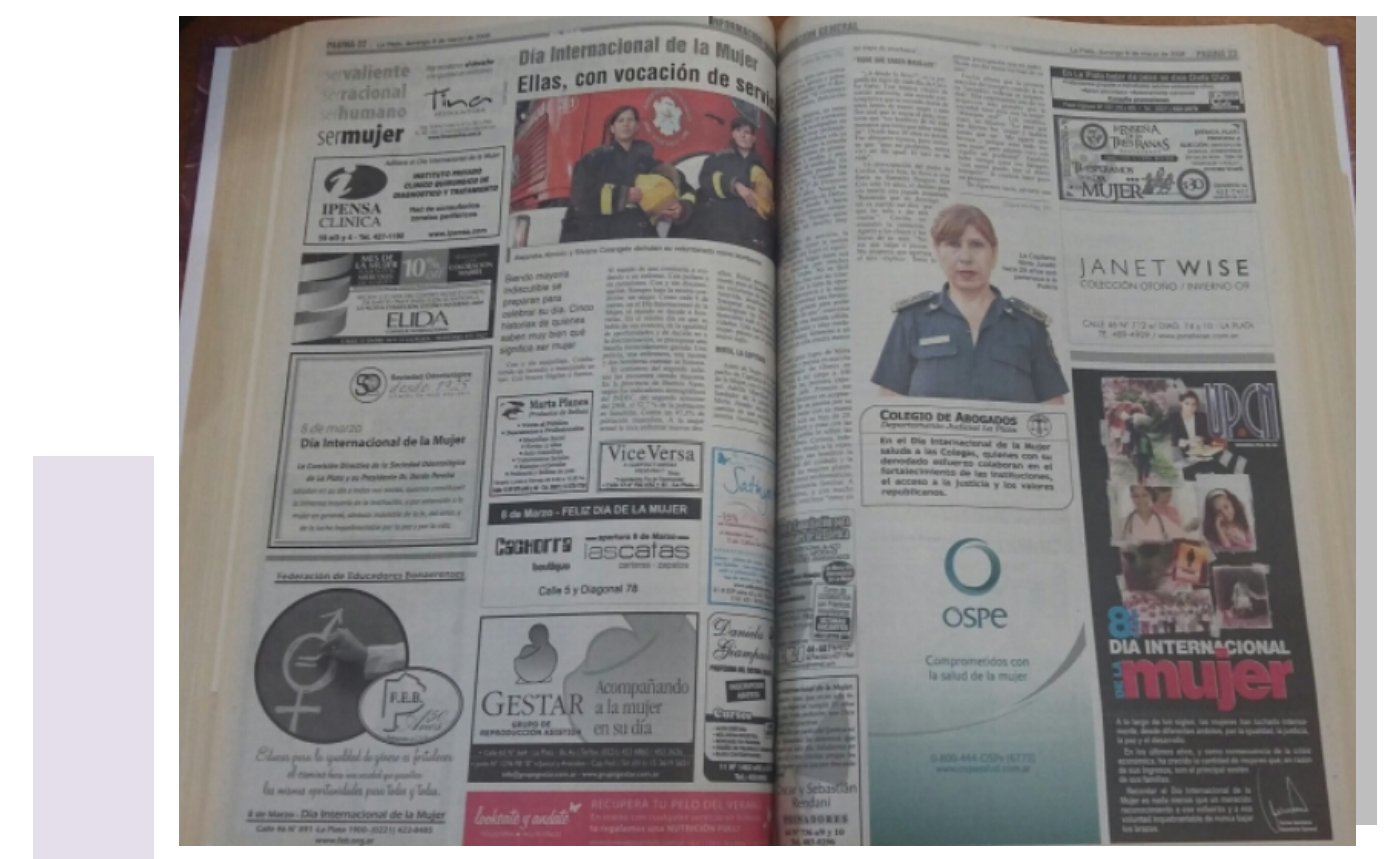

Figura 2. «Ellas, con vocación de servicio»

El Día, 8 de marzo de 2009, páginas 22 y 23

A cien años de la proclamación del Día Internacional de la Mujer, que tuvo lugar durante la II Conferencia Internacional de Mujeres Socialistas, realizada en Copenhague bajo el lema del sufragio universal, el diario centra la noticia de su portada en un informe de la Jefatura de Gabinete del gobierno de la Provincia de Buenos Aires según el cual La Plata es la ciudad que cuenta con mayor cantidad de investigadoras científicas. A este dato, que se deduce de la alta proporción que obtiene la ciudad en las becas provinciales destinadas a mujeres (60\%), se suma la estimación de un crecimiento de su presencia en los laboratorios (10\%).

La nota, titulada «Una historia que cumple cien años», centra la atención en cómo las mujeres han multiplicado sus áreas de investigación sobre las históricamente consideradas masculinas, en especial en el ámbito de las ciencias «duras». Sin embargo, se advierte que estos avances no se reflejan en la dirección de los centros o los grupos de investigación. 
En línea con la lógica del año anterior, nuevamente, aparece la figura de una mujer que avanza sobre el lugar del hombre, pero no una crítica a la conformación de esas feminidades / masculinidades. Mientras tanto, en la sección Policiales, el femicidio de un remisero a su esposa es titulado como drama pasional.

Este año, no hay ninguna mención en la portada. Recién en la página 17 se narra el proceso de luchas acontecidas durante el siglo XIX, en reclamo por un lugar de participación social en igualdad con el hombre, que le dieron forma al Día Internacional de la Mujer. En la nota «Conmemoración de una lucha por la igualdad» se destaca el derecho al trabajo, al voto y a ocupar cargos públicos, y se relatan el incendio de la fábrica Triangle en la ciudad de Nueva York, en 1911, y la huelga rusa, de 1917, en demanda por «pan y paz».

Entre las voces que el diario incluye figura la del entonces Jefe de Gobierno de la Ciudad Autónoma de Buenos Aires, y actual presidente de la nación, Mauricio Macri, quien expresa: «Queremos rendir homenaje a nuestras mujeres, que son un ejemplo de compromiso y de sensibilidad, y que tanto trabajan todos los días para que los argentinos tengamos una sociedad más inclusiva y un país mejor». Se consignan, también, declaraciones de la gobernadora de Tierra del Fuego, Fabiana Ríos, primera mujer electa gobernadora en el país, quien se refiere a las injusticias que sufren las mujeres.

Entre las actividades realizadas en la ciudad, sobresalen las mil fotos de personalidades femeninas y los múltiples talleres sobre los derechos de las mujeres dictados en diferentes instituciones. A esto se suman el festival «Por todo lo conquistado, por más derechos» y la Campaña Nacional por el Derecho al Aborto Legal, Seguro y Gratuito que contó con una radio abierta en Plaza Moreno. 
En distintas secciones, el diario publica este año siete notas referidas al Día Internacional de la Mujer. En Interés general, la nota «Conmemoración de una lucha por la igualdad» historiza, brevemente, por qué el 8 de Marzo se conmemora el Día de la Mujer y concluye que, más allá del dato histórico, lo que se homenajea es la lucha de las mujeres por la igualdad.

En la sección Interés General, la nota titulada «Día de la mujer: un nuevo llamado por la igualdad» retoma la voz del por entonces Secretario General de la ONU, Ban Ki-moon, en el marco de la celebración oficial del Día Internacional de la Mujer Trabajadora. Lo que se expone es la desigualdad que experimentan las mujeres (como un único sujeto político de la lucha) en relación con la representación política, el acceso al trabajo y la educación. El eje de la nota está dado por la necesidad de alcanzar la igualdad respecto de los hombres.

En esta misma sección, en la nota «"Día de la mujer" entre homenajes, protestas y festejos» se describe la situación en materia de problemáticas de género en países de Asia y de Oceanía. Situadas en estos países, las desigualdades que se mencionan generan una idea de lejanía respecto de lo que sucede en la Argentina; construyendo el relato de la gravedad que atraviesan las mujeres en esos países comparable con las condiciones en las que viven las mujeres en la Argentina.

En el editorial, titulado «El Día de la Mujer, una fecha para renovar el compromiso por la igualdad», el diario aborda el 8 de Marzo como un día de celebración que se presenta como «un justo homenaje a los esfuerzos y sacrificios realizados durante décadas para contribuir a la igualdad entre las mujeres y los hombres». El lugar de las mujeres aparece vinculado al sacrificio y a la superación, y la discriminación es presentada como un «flagelo» frente al cual las acciones para combatirlo se sintetizan en realizar «un cambio duradero de los valores y las actitudes».

El único espacio en el que se menciona algo de la escena local es la sección La Ciudad. No obstante, la nota, publicada bajo el título «Distinguen a 16 mujeres de distintos barrios de la Ciudad», se reduce a mencionar el «reconocimiento», mediante «diplomas y posters», a mujeres de distintos puntos de la ciudad por su labor solidaria. En esta misma línea, se publica una agenda de eventos, de homenajes y de actividades culturales a desarrollarse en el marco del Día del Mujer. 
El diario publica una nota de opinión "La mujer emprendedora», firmada por Martín Ferré, ministro de Desarrollo Social de la Provincia de Buenos Aires, en la que el funcionario considera que «es justo homenajear a la mujer emprendedora [que es] la que sostiene a su familia, la que conoce de sacrificios, la que se atreve a concretar sus proyectos». A partir de esta definición, menciona las características inherentes a «la mujer emprendedora»: es militante, sabia, vive abocada a su familia, lucha por sus derechos, entre otras.

Otra nota de opinión, titulada «Del voto femenino a la ley del 2012» y firmada por la periodista Marta Gordillo, ofrece una breve reseña sobre la lucha de las mujeres en los últimos sesenta años, centrándose en la conquista del voto femenino. Se trata de la única nota en estos dos años en la que se construye un marco explicativo que describe la «ideología machista y discriminatoria» o las "formaciones sociales patriarcales que le asignaron a la mujer un lugar de subordinación» (en línea).

Por último, en una nota breve, titulada "Una feminista pionera y rioplatense», se menciona la trayectoria de María Abella de Ramírez, quien «concibió a fines del siglo XIX el "Programa Mínimo de Reivindicaciones Feministas"» y fundó la Primera Federación Femenina Panamericana.

En la tapa del 8 de Marzo de 2014 no se ofrecen imágenes ni de marchas ni de colectivas feministas pidiendo por más derechos; la única presencia femenina es la de la ex presidenta Cristina Fernández de Kirchner anunciando una futura reunión con el Papa Francisco. La portada se completa con informaciones sobre una marcha en la localidad de Lisandro Olmos, por el miedo que genera la inseguridad; un paro docente universitario; un conflicto en el ámbito laboral penitenciario; y el aniversario del diario. 
A pesar de esto, una de las notas más extensas -cuenta con cuatro páginases «Cómo sobrevivir en un mundo de hombres», escrita en la sección de Información General por Leandro Savoretti, quien da cuenta de los trayectos biográficos de mujeres «inusuales» que marcaron la ciudad: una colectivera, una carnicera y una periodista deportiva. Cargada de recursos afectivos y con la figura de la mujer como protectora de toda familia, estos trayectos biográficos son realzados en el texto por las cualidades «más masculinas» que estas mujeres tuvieron que «fortalecer»: manejar máquinas grandes y filosas, romper con estereotipos y con costumbres, entre otras. A lo largo del texto, se recae constantemente en el recurso de halagar las cualidades que se entienden propias del género masculino.

La edición cuenta, en la página 6, con una columna titulada «En el Día de la Mujer: alarma en el crecimiento de femicidios en el país», en la que se brindan datos cuantitativos al respecto pero sin mayor análisis sobre los mismos.

La segunda nota dedicada a la particularidad de la fecha, publicada en la sección La ciudad bajo el título "Nutrida agenda en la Ciudad para celebrar el día de la mujer», enumera las actividades artísticas que se desarrollarán durante la jornada en teatros, en centros culturales y en espacios municipales de la ciudad. Cabe resaltar la ausencia de actividades artísticas o de expresiones populares en la vía pública.

Como temática de interés, una nota titulada «Recomiendan educación sexual desde los 12 años» (p. 2) aborda la preocupación manifestada por la Organización Mundial de la Salud y por la Organización de las Naciones Unidas sobre la necesidad de que se les brinde educación sexual integral a jóvenes a partir de los 12 años. Luego de este dato, la nota recopila normativas jurídicas y legales, así como programas nacionales que trabajan la temática en instituciones educativas públicas y privadas. Al final del texto, se señala que «la ley resulta controvertida y ha sido criticada por la Iglesia» (p. 2) y se marca que en 2006 se sancionó en la Argentina la Ley Nacional 26.150 que creó el Programa Nacional de Educación Sexual Integral. 
En diametral diferencia con el año previo, la tapa de 2015 gira en torno a la jornada de lucha de las mujeres. «Las mujeres, con sueldos más bajos que los hombres», anuncia el titular, que cita cifras del Instituto Nacional de Estadística y Censos (INDEC). Debajo, sin embargo, una foto del bailarín Hernán Piquín, junto a una mujer mayor y a una flor amarilla, reza: «Piquín bailó para ellas en La Plata».

La nota que recupera las cifras del INDEC se desarrolla en la sección Interés General. Con una volanta que indica: «Se celebra hoy el día de la mujer en el medio de una profunda inequidad», se ofrecen gráficos, números y porcentajes que dan cuenta de una gran brecha salarial. Se incluye, también, información local: según la nota, en la Universidad Nacional de La Plata (UNLP) las que más se gradúan son las mujeres, lo que a posteriori no se refleja en el campo laboral. En este sentido, se pregunta por las desigualdades que se sostienen a pesar de ser las más capacitadas en las distintas áreas académicas.

En esta misma sección, el diario ofrece una nota de menos de diez líneas firmada por Estela Díaz, Secretaria de Género de la Central de Trabajadores de la Argentina (CTA) y, por ese entonces, coordinadora del Centro de Estudios Mujeres y Trabajo. Bajo el título «Es necesario redistribuir las tareas del hogar», la autora aborda la temática de la brecha salarial entre hombres y mujeres.

Sobre el final, la sección cuenta con un artículo titulado «Usan el vestido viral para una campaña contra violencia de género» en el que se reflexiona sobre la campaña de The Salvation Army, ${ }^{2}$ en la que se muestra a una mujer que lleva un vestido dorado y blanco, y que presenta moretones en su rostro y en sus piernas. Acompaña la imagen la pregunta: «¿Por qué cuesta tanto ver negro y azul?» [Figura 3]. Aunque se hace hincapié en la viralidad de la campaña, no se reflexiona ni sobre el contenido ni sobre el mensaje. 


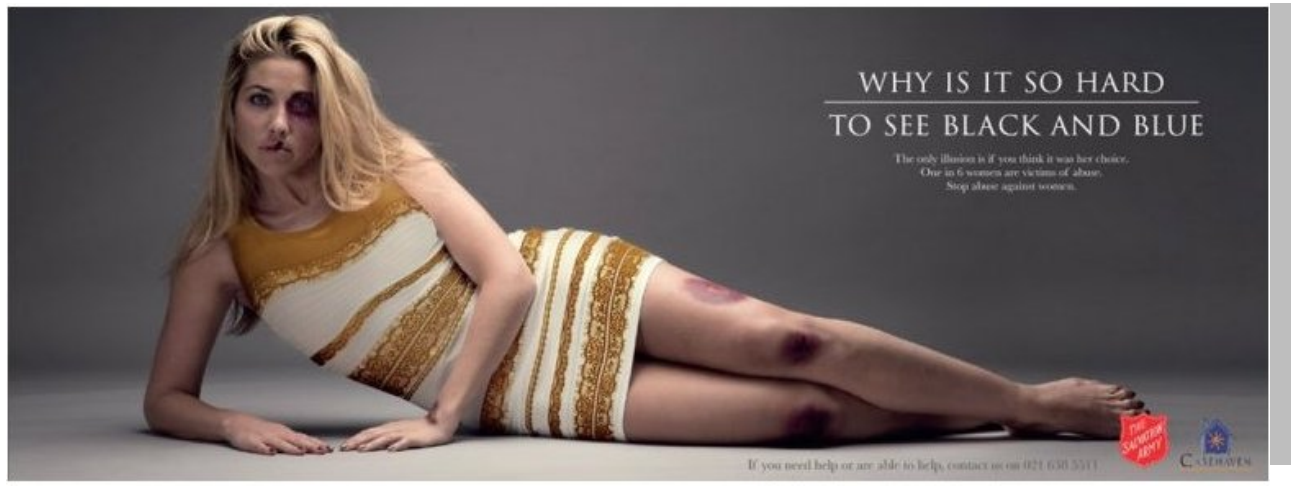

Figura 3. Imagen de la campaña de The Salvation Army, cuyo hashtag \#StopAbuseAgainstWomen alcanzó en quince horas más de 11.000 retuits

En la sección El Mundo, con el título «Francisco: "Un mundo que margina a las mujeres es un mundo estéril"», se reproducen las palabras del Papa Francisco, quien se refiere a la figura de la mujer como aquella que porta el género «con corazón más creativo, más paciente y más tierno» (p. 2).

Por último, el bailarín Hernán Piquín, que ilustra la tapa del día, cuenta con una nota sobre su espectáculo «Homenajeando a las mujeres» (p. 1), que se realizó en el Pasaje Dardo Rocha y al que asistieron más de cuatro mil personas.

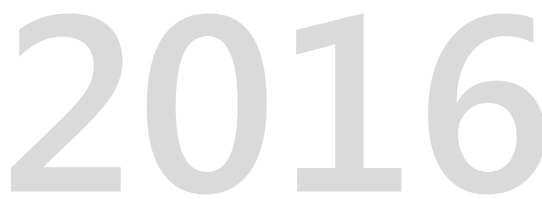

La cobertura por la conmemoración del Día Internacional de la Mujer se construye este año en la tapa de la edición impresa con un título -ubicado en la parte superior, no central- que informa: «Hay 500 denuncias diarias por ataque contra mujeres», y una bajada en la que se detalla que estos datos surgen de un informe de la Defensoría del Pueblo de la provincia de Buenos Aires. La nota continúa en las páginas 16 y 17, de la sección Sociedad, con el título «El duro trasfondo de la Mujer» [Figura 4]. Ni en los títulos ni en los subtítulos se hace referencia a la violencia de género como problema social y político, sino que se sugiere la fragmentación a partir de visibilizar las denuncias por ataques puntuales. 


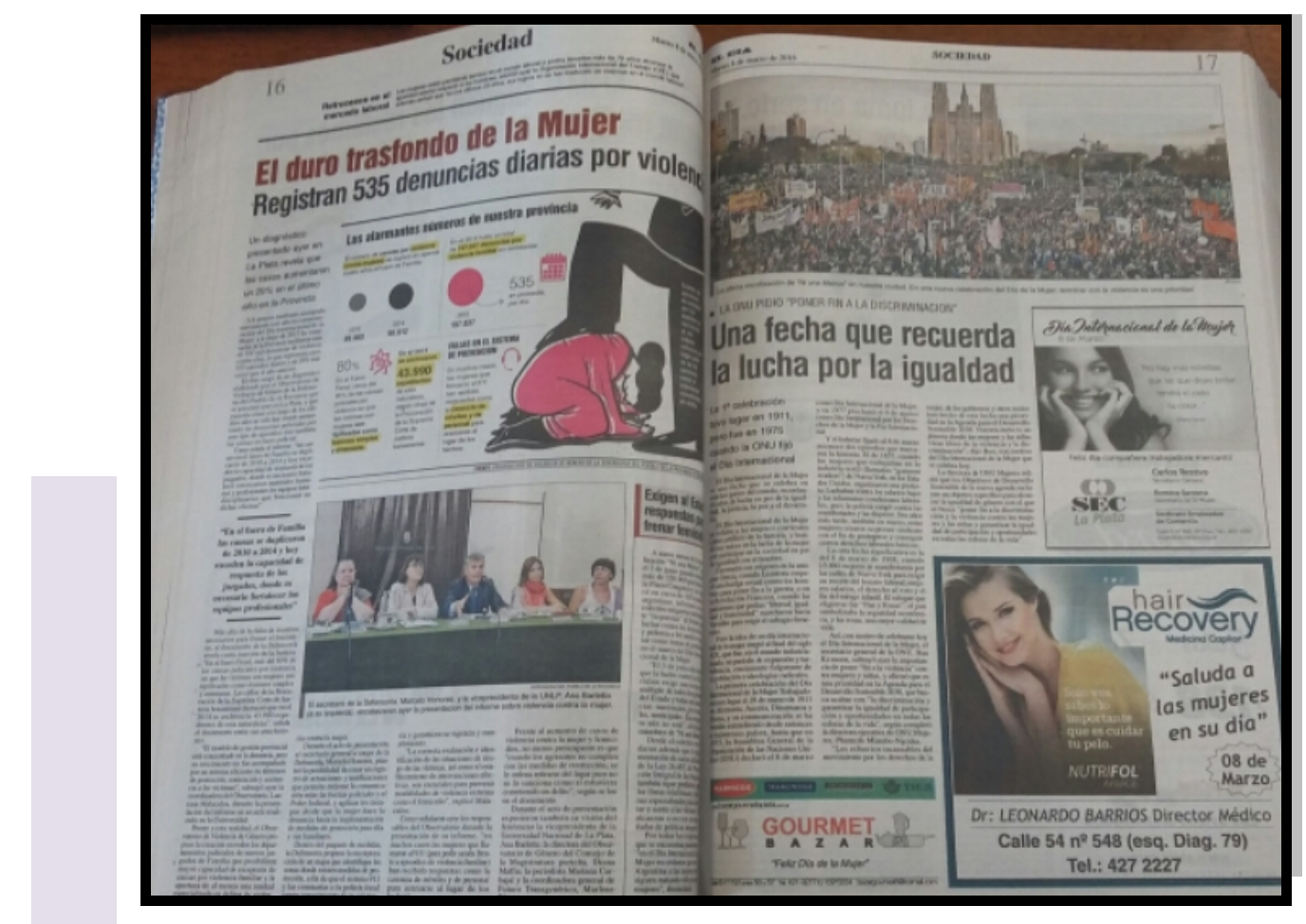

Figura 4. «El duro trasfondo de la Mujer»

El Día, 8 de marzo de 2016, páginas 16 y 17

En la parte central de la tapa, con una imagen familiar (mamá, papá e hijas) y bajo el título «Juanita en su casa con un nuevo corazón», se otorga centralidad a la noticia de la nena trasplantada que estuvo en lista de espera y que fue dada de alta. Se advierte una intención editorial de desplazar la atención hacia esta noticia, dada la sensibilidad del tema y el peso de la imagen familiar.

En lo que respecta al portal, a lo largo del día se registran notas que dan cuenta de las manifestaciones y las actividades desarrolladas durante la jornada en conmemoración por el 8M. En el orden local, provincial y nacional, se levantan declaraciones de funcionarias y funcionarios gubernamentales que se pronunciaron sobre el tema. En ese sentido, en la nota «Implementarán una red de refugios para las víctimas de violencia de género», que aparece acompañada de una imagen del rostro de la gobernadora María Eugenia Vidal, se anuncia que la Provincia implementará una red de refugios para víctimas de violencia de género. Si bien el desarrollo de la noticia da cuenta de la preexistencia de estos refugios, el titular lo destaca como el anuncio de una nueva medida, sin reconocer estos antecedentes. 
En cuanto a la ciudad de La Plata, en la nota «Actividades y distinciones por el Día de la Mujer en la Región» se cubre la participación del intendente Julio Garro en «las distintas actividades con motivo de homenajear a las ciudadanas platenses» y se citan sus declaraciones: «Celebramos la valentía de la mujer por enfrentar un sistema injusto».

En el orden nacional, se levantan declaraciones de la jueza de la Corte Suprema de Justicia, Elena Highton, a favor del uso de una "pulsera» para controlar a los victimarios. En la nota, titulada «Elena Highton: no hay "una protección cien por cien" contra la violencia de género», se mencionan las actividades y las declaraciones del presidente Mauricio Macri alusivas a la fecha, en las que el mandatario se refirió a la necesidad de generar líneas de trabajo para ampliar el protagonismo de las mujeres, sobre todo en el campo social y laboral.

Sobre el final del día se publica en el portal la noticia «Diputadas del FPV piden la liberación de Milagro Sala», que aborda el pedido de las legisladoras del Bloque Nacional Frente para la Victoria-PJ quienes, junto con dirigentes sociales de diferentes agrupaciones, pidieron por la liberación de Milagro Sala: «No hay conmemoración del Día de la Mujer sin la liberación de Milagro Sala».

Es importante señalar que 2016 fue el primer año de gestión del gobierno de la alianza Cambiemos y se advierte con facilidad una impronta del diario por visibilizar el rol de sus principales mandatarios y mandatarias (presidente, gobernadora e intendente) en esta fecha.

Para los/as editores/as del diario El Día, en 2017 el Día Internacional de la Mujer no presenta mayor relevancia, ya que en su tapa y como nota central optan por publicar la imagen de los incidentes ocurridos el día anterior en la masiva movilización de la CGT (Confederación General del Trabajo de la República Argentina), en la que se anunció un paro general. En la parte superior, en tanto, con un gran titular y sin imagen, se informa: «Sigue el paro docente». ${ }^{3}$ Solo en la parte inferior, con letras e imágenes muy pequeñas, se hace referencia al día de la mujer con el titular «Mujeres que son un orgullo para la comunidad». Ilustrada 
con el rostro de tres mujeres con atuendo de enfermeras, el texto resalta la enorme entereza y la solidaridad de estas mujeres que, de acuerdo a las/os editoras/es, son representativas de muchas otras mujeres. Bajo el título «Entrega y vocación de servicio, otra forma como ellas brindan amor», la nota continúa como artículo central por el 8M en las páginas 18 y 19 [Figura 5]. En página 17, con el título «Las mujeres celebran su día con un inédito paro internacional», se hace un breve desarrollo de la jornada de protesta.

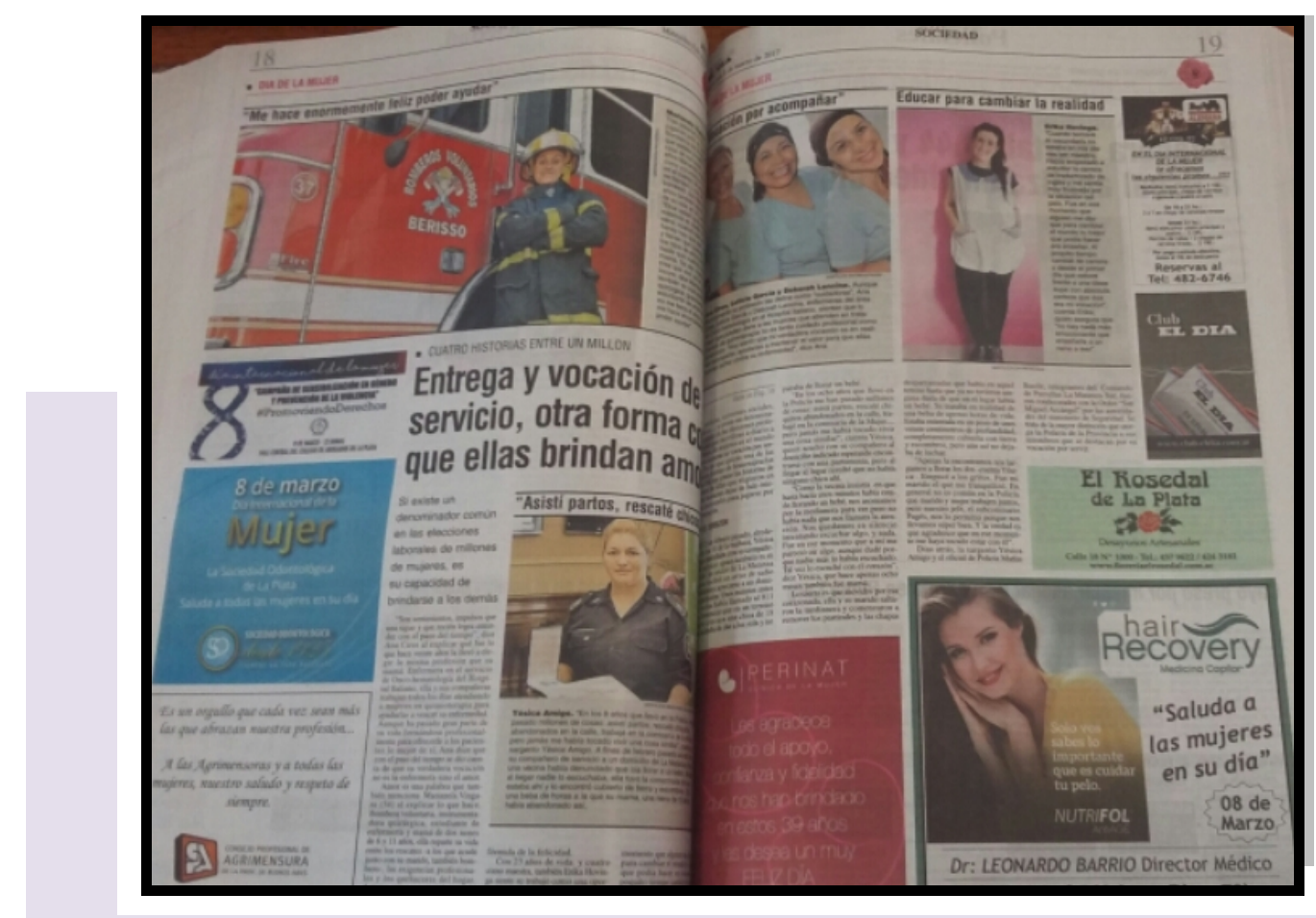

Figura 5. «Entrega y vocación de servicio, otra forma con la que ellas brindan amor» El Día, 8 de marzo de 2017, páginas 18 y 19

Nuevamente, se corre este día de su carácter de hecho político y se lo ubica en un lugar donde se priorizan la individualidad, los logros personales, la lucha «en soledad» y no su carácter de movimiento colectivo. Se resalta una perspectiva que remarca el rol de la mujer como eterna cuidadora, solidaria, valiente y luchadora, instalando un estereotipo del cual, según el diario, la sociedad debe enorgullecerse y, por lo tanto, homenajear a la mujer en su día. 
Como en años anteriores, durante toda la jornada se publicaron en el portal del diario notas sobre las distintas movilizaciones que se realizaron en el país y en el mundo. Entre ellas, con el título «En Plaza de Mayo miles de mujeres dijeron Ni Una Menos», se informa sobre la marcha que se realizó en la Ciudad Autónoma de Buenos Aires bajo la consigna inaugurada el 3 de junio de 2015 para visibilizar la lucha y el reclamo por políticas públicas contra la violencia de género.

Las notas siguen sin aparecer en la sección Política, solo ocupan las secciones de Información General y El Mundo. En los titulares no se hace mención al reclamo por la Ley de Interrupción Voluntaria del Embarazo, una de las principales reivindicaciones de la jornada de protesta.

Con una nota ubicada en la parte inferior de la portada, sin imagen y con el título en letras pequeñas que indica "Las mujeres de todo el país marchan por sus derechos», el diario inaugura esta nueva edición del 8M. En cambio, con imagen y un titular de letras más grandes, la parte central de la portada es ocupada por un nuevo episodio de delito: «Dos horas de terror en el Centro por otro ataque de "los pibes piraña"».

Este año, la nota central sobre el 8M se encuentran en la sección Deportes: bajo el título «Carla Belén López, la platense que busca romper los prejuicios del arbitraje argentino», se ofrece la foto de una mujer árbitra de fútbol cuya imagen radiante busca reflejar la fuerza de las mujeres a quienes les toca enfrentar todos los obstáculos del mundo "futbolero masculino», en donde es un hecho la discriminación y la desigualdad para la inserción laboral de las mujeres.

En las páginas centrales se incluyen dos notas: una presenta un informe con cifras sobre feminicidios que, sin embargo, no aparecen así enunciadas, sino como «La violencia machista se cobra la vida de 260 argentinas al año» (p. 16); otra, un informe sobre la jornada de paro y de protesta «El \#8M se hizo sentir en todo el país con multitudinarias marchas» (p. 17). En otras dos páginas (14 y 15) se ofrece una nota que se titula «Historias de mujeres cuyos objetivos inspiran y realzan el valor de la igualdad». 
Al mismo tiempo, y como lo refleja el detalle de las distintas notas y crónicas descriptas, durante todo el día la cobertura del diario sobre las distintas manifestaciones reflejó la jornada de paro y de protesta en el país y en el mundo, otorgando un carácter más «político» y masivo a este movimiento.

Si bien en el portal las notas que ofrecieron la cobertura sobre la jornada correspondieron a la sección Sociedad e Información General, una de ellas se ubica en la sección Política y Economía, con una declaración del presidente Mauricio Macri. Bajo el título "8M: Macri anunció el envío de un proyecto para "lograr el salario igualitario"», se indica que según declaró el ex Presidente durante el acto oficial por el 8M la iniciativa busca «avanzar en la equidad de la ley de género».

Pese a que el movimiento feminista argentino avanza en la organización y en la lucha por sus demandas, el 8 de Marzo de 2019 la nota central de tapa se la llevó el dólar, que durante el gobierno de Cambiemos experimentó una escalada histórica.

En un pequeño recuadro, ubicado en el margen inferior de la tapa, el adelanto de una de las notas que se desarrolla en el interior advierte que durante 2018 se cometió un femicidio cada 32 horas y que en lo que va de ese año se registraron 43 casos: 21 en enero, 14 en febrero y 8 en marzo -mes que acababa de comenzar-. Estos datos corresponden al Observatorio de Femicidios en Argentina, Marisel Zambrano, de la Casa del Encuentro [Figura 6]; relevamientos de otras organizaciones feministas oscilan entre 45 y 54 femicidios, y 15 travesticidios.

Dicha nota también alude al reclamo que las organizaciones de mujeres y disidencias vienen realizando por el escaso presupuesto destinado por el Estado a cuestiones de género y por la falta de políticas transversales que puedan incidir en esta situación. Menciona, también, la necesidad de otorgar un subsidio para las víctimas de violencia, la correcta implementación de la Ley Nacional 26.150 de Educación Sexual, el urgente tratamiento del Proyecto de Ley de Interrupción Voluntaria del Embarazo, la creación de fueros especializados en violencia de género y la implementación de la Ley Micaela, entre otras banderas propias del movimiento feminista. 
Los casos en lo que va del año

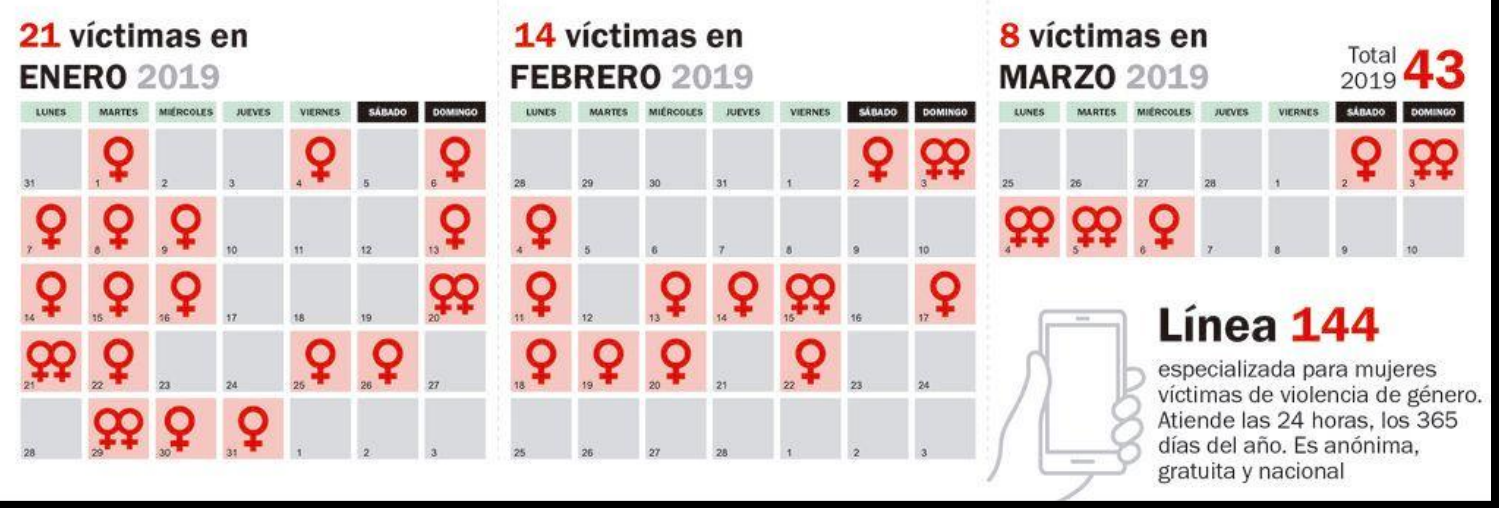

Figura 6. Datos del informe elaborado por Casa del Encuentro

El Día, 8 de marzo de 2019, portada

En el portal, la nota central es sobre el «Pata» Medina, quien «dejó la cárcel por un rato», y se presenta acompañada de una foto que atrae la mirada. En un recuadro pequeño, ubicado en el margen derecho, se ubica el título «Con actos, charlas y una marcha, las mujeres de la región se suman al 8M». Al acceder a la nota, tanto en la volanta como en la bajada se menciona que se trata de una jornada que «cada vez moviliza más» y que el punto de encuentro es Plaza Moreno -aunque la foto que acompaña el texto es sobre una intervención realizada por mujeres en las escalinatas del Banco Provincia-. La posición del diario queda expresada en el primer párrafo, en el que se indica que la fecha se encuentra «lejos del romanticismo que expresó en otros tiempos y reconvertida en una fecha de reclamos», desconociendo el largo historial del feminismo en la ciudad de La Plata.

De las cuatro notas de opinión que se publican en la edición impresa, las dos centrales se refieren a temas que forman parte de la agenda actual: «Mujeresniñas: ¿madres?» $\mathrm{y}$ «Todos los derechos, todas las Mujeres siempre», cuya autora es Fabiana Tuñez, titular del Instituto Nacional de las Mujeres. Más abajo, compartiendo espacio con el paro docente, se desarrolla la nota anunciada en tapa: «Un femicidio cada 32 horas, la realidad de un flagelo que conmueve a la sociedad», acompañada de una fotografía fuera de foco en la que se puede distinguir a una mujer en el piso y a un hombre parado tomándola del cabello. Para el diario la violencia es «flagelo», y lejos está de posicionar el tema como un problema social de derechos humanos. 


\section{Consideraciones generales}

Durante estos diez años, para el diario El Día la construcción del sentido del 8 de Marzo aparece, en principio, en relación con la búsqueda de igualdad con los hombres. Como bien se señala en la última nota publicada en su portal de noticias, el diario ha pasado de ver la fecha como algo «romántico» a tener que dar cuenta de la amplia movilización feminista.

El género es pensado en términos binarios y no hay una explicación compleja de las problemáticas de género; están ausentes las palabras heteronormatividad y patriarcado, así como la lucha por el aborto.

Lo local se encuentra vinculado a la entrega de reconocimientos y a la realización de homenajes a mujeres particulares, y no se mencionan acciones del Estado que contengan las problemáticas de género. La construcción de la mujer-heroína, del esfuerzo femenino como algo que hay que premiar, da lugar a un discurso de autosuperación personal que hace foco en la conducta individual de cada persona y no en la desigualdad estructural del sistema patriarcal.

La mujer se presenta en clave de biologización de lo femenino y en vinculación con la entrega a los otros: las mujeres son enfermeras.

Tampoco se da cuenta de la agenda de demandas locales, provinciales o nacionales de los colectivos y las organizaciones, excepto en la última nota de 2019 en la que se recuperan algunas en la voz de la directora de Casa del Encuentro, Ada Beatriz Rico, en el marco de la cobertura de un acto de presentación de un informe sobre femicidios. En muy pocas notas se hace referencia a datos estadísticos sobre las problemáticas de género en estos ámbitos. La cuestión de la situación de las mujeres en un mercado de trabajo masculinizado es abordada de una forma absolutamente superficial; en todos los casos, se hace foco de manera sexista en la división genérica del trabajo: trabajo de hombres y trabajo de mujeres.

Las voces autorizadas para hablar del 8 de Marzo son la ONU o los varones que escriben los editoriales y las notas de opinión del diario; en 2019, por primera vez, se publican notas de opinión firmadas por mujeres. Tampoco hay entrevistas ni citas o referencias provenientes de las mujeres protagonistas. 
El diario El Día describe la lucha de mujeres de otros países que tienen la brecha de desigualdad de género más profunda y minimiza las problemáticas de violencia y de discriminación en la Argentina.

De esta forma, si bien se reconocen cambios en el tratamiento mediático a partir de la incidencia que el movimiento feminista argentino tiene en la agenda mediática actual, aún quedan muchos desafíos para afrontar con respecto a un tratamiento mediático con perspectiva de género, así como para la conformación de una planta periodística formada en la materia. También, se reconoce la necesidad de que las compañeras periodistas que participan en organizaciones feministas y que promueven los derechos de las mujeres y disidencias puedan ocupar lugares jerárquicos en la toma de decisiones de los diarios tradicionales de la ciudad.

\section{Fuentes consultadas}

\section{9}

Con homenajes y reclamos se celebra el Día internacional de la mujer, p. 1.

Ellas, con vocación de servicio, pp. 22-23.

Día de la Mujer: una de cada tres es víctima de abusos en el mundo

2010

Una historia que cumple cien años

2011

Conmemoración de una lucha por la igualdad

2012

Día de la mujer: un nuevo llamado por la igualdad

«Día de la mujer» entre homenajes, protestas y festejos

El Día de la Mujer, una fecha para renovar el compromiso por la igualdad

Distinguen a 16 mujeres de distintos barrios de la Ciudad

2013

La mujer emprendedora

«Del voto femenino a la ley del 2012»

«Una feminista pionera y rioplatense» 
Cómo sobrevivir en un mundo de hombres

En el Día de la Mujer: alarma en el crecimiento de femicidios en el país

«Nutrida agenda en la Ciudad para celebrar el día de la mujer»

Recomiendan educación sexual desde los 12 años, p. 2.

2015

Las mujeres, con sueldos más bajos que los hombres, p. 1.

«Piquín bailó para ellas en La Plata», p. 1.

Estela Díaz: «Es necesario redistribuir las tareas del hogar»

Usan el vestido viral para una campaña contra violencia de género

Francisco: «Un mundo que margina a las mujeres es un mundo estéril»

Homenajeando a las mujeres, p. 1.

2016

Hay 500 denuncias diarias por ataque contra mujeres, p. 1.

El duro trasfondo de la Mujer, pp. 16 y 17.

Implementarán una red de refugios para las víctimas de violencia de género

Actividades y distinciones por el Día de la Mujer en la Región

Elena Highton: «No hay "una protección cien por cien” contra la violencia

de género»

«Diputadas del FPV piden la liberación de Milagro Sala»

2017

Mujeres que son un orgullo para la comunidad, p. 1.

Entrega y vocación de servicio, otra forma como ellas brindan amor

Las mujeres celebran su día con un inédito paro internacional

En Plaza de Mayo miles de mujeres dijeron Ni Una Menos

2018

Las mujeres de todo el país marchan por sus derechos, p. 1.

Carla Belén López, la platense que busca romper los prejuicios del arbitraje argentino

La violencia machista se cobra la vida de 260 argentinas al año

El \#8M se hizo sentir en todo el país con multitudinarias marchas

Historias de mujeres cuyos objetivos inspiran y realzan el valor de la igualdad

8M: Macri anunció el envío de un proyecto para «lograr el salario igualitario

2019

Con actos, charlas y una marcha, las mujeres de la región se suman al 8M

Mujeres-niñas: ¿madres?

Todos los derechos, todas las Mujeres siempre

Un femicidio cada 32 horas, la realidad de un flagelo que conmueve

a la sociedad 


\section{Referencias}

Amnistía internacional (1 de marzo de 2019). Caso «Lucía»: pedido de informes a la Secretaría de Derechos Humanos de Tucumán por violencia institucional. Recuperado de https://amnistia.org.ar/caso-lucia-pedido-de-informes-a-la-secretariade-derechos-humanos-de-tucuman-por-violencia-institucional/

Casa del Encuentro (2018). Informe de investigación de femicidios en Argentina 2008-2017. Recuperado de http://www.lacasadelencuentro.org/descargas/femicidios-10-anios.pdf

Comité de América Latina y el Caribe para la Defensa de los Derechos de la Mujer (CLADEM) (2016). Niñas Madres. Embarazo y maternidad infantil forzada en América Latina y el Caribe. Recuperado de https://cutt.ly/MQZIIk

Comité de los Derechos del Niño de Naciones Unidas (1 de octubre de 2018). Observaciones finales sobre los informes periódicos quinto y sexto combinados de la Argentina. Recuperado de https://cutt.ly/aQCjOz

Cooperativa de Comunicación Feminista Manifiesta (2019). \#AbajoElAjuste [entrada de facebook]. Recuperado de https://www.facebook.com/manifiestacomunicacion/posts/2068294463 $285811 /$

Goren, N. y Trajtemberg, D. (noviembre de 2018). Brecha salarial según género. Una mirada desde las instituciones laborales. Recuperado de http://library.fes.de/pdffiles/bueros/argentinien/14882.pdf 
Ley Nacional 26.150 (2006). Programa Nacional de Educación Sexual Integral. Boletín Oficial de la República Argentina.

Buenos Aires, 24/10/2006. Recuperado de

http://servicios.infoleg.gob.ar/infolegInternet/anexos/120000-

124999/121222/norma.htm

Ley Nacional 26.743 (2012). Identidad de Género. Boletín Oficial de la República Argentina. Buenos Aires, 09/05/2012.

Recuperado de

http://servicios.infoleg.gob.ar/infolegInternet/anexos/195000199999/197860/norma.htm

Ley Nacional 27.499 (2019). Ley Micaela de Capacitación Obligatoria en Género para todas las Personas que Integran los tres Poderes del Estado. Boletín Oficial de la República Argentina. Buenos Aires, 10/01/2019.

Recuperado de

http://servicios.infoleg.gob.ar/infolegInternet/anexos/315000319999/318666/norma.htm

Muñiz García, E. (1999). La cultura de género en la era de la democracia. Omnia (s/d). Recuperado de www.posgrado.unam.mx/publicaciones/ant_omnia/41/05.pdf

Sandá, R. (25 de enero de 2019). La niña objeto. Página/12. Recuperado de https://www.pagina12.com.ar/170383-la-nina-objeto

Télam (30 de mayo de 2019). Registraron un femicidio cada 24 horas en este primer cuatrimestre. Recuperado de https://www.telam.com.ar/notas/201905/362778-un-observatorio-deviolencia-registro-un-femicidio-cada-24-horas-en-este-primercuatrimestre.html 
Oficina del Alto Comisionado para los Derechos Humanos

(ACNUDH) de Naciones Unidas (6 de junio de 2018). Concluyó

el $78^{\circ}$ período de sesiones en Ginebra (Suiza). Recuperado de

http://acnudh.org/comite-onu-realizo-observaciones-a-argentina-

sobre-derechos-de-la-infancia/

Programa Nacional de Salud Integral en la Adolescencia (2017).

Niñas y adolescentes menores de 15 años embarazadas. Recuperado

de www.msal.gob.ar/images/stories/bes/graficos/0000001079cnt-

ninas-dolescentes-menores-15-anos-embarazadas.pdf

Shokida, N. (2019). La desigualdad de género se puede medir.

Recuperado de http://economiafeminita.com/la-desigualdad-de-

genero-se-puede-medir-3/

Notas

1 Este dato, que alude al discurso pronunciado el 1 de marzo de 2020 por el presidente Alberto Fernández ante la Asamblea Legislativa en la apertura de sesiones del período 138, fue incluido a solicitud de las autoras durante el proceso de maquetación de este artículo.

2 El Ejército de Salvación es una organización no gubernamental de beneficencia social privada.

3 Vale mencionar que, en los últimos años, el no inicio de clases a raíz del paro docente, es un tema recurrente en las tapas del diario. 